Supporting Information

\title{
Photoinitiated Cationic Ring-Opening Polymerization of \\ Monothiocarbonate
}

Nihan Yonet ${ }^{1}$, Yusuf Yagci ${ }^{1}$, Bungo Ochiai ${ }^{2}$, Takeshi Endo ${ }^{2}$

${ }^{1}$ Istanbul Technical University, Department of Chemistry, Maslak, Istanbul 80626, Turkey

${ }^{2}$ Department of Polymer Science and Engineering, Faculty of Engineering, Yamagata University, 4-3-16 Jonan, Yonezawa, Yamagata 992-8510, Japan

\section{Experimental}

Materials:

Monothiocarbonate, 5,5-dimethyl-1,3-dioxane-2-thione (DDT) was prepared as described previously ${ }^{1}$. Dichloromethane (99.8 \%, J.T.Baker) as the 
polymerization solvent was washed successively with sulfuric acid, water, and $5 \% \mathrm{NaOH}$ solution. It was then dried over $\mathrm{CaCl}_{2}$ and $\mathrm{CaH}_{2}$ and finally distilled by fractionation column. Diphenyliodonium hexafluorophosphate ${ }^{2}$ $\left(\mathrm{Ph}_{2} I^{+} \mathrm{PF}_{6}^{-}\right)$, triphenylsulfonium hexafluoroarsenate ${ }^{2}\left(\mathrm{Ph}_{3} \mathrm{~S}^{+} \mathrm{AsF}_{6}^{-}\right)$and $\mathrm{N}-$ ethoxy-2-methylpyridinium hexafluorophosphate ${ }^{3} \quad\left(\mathrm{EMP}^{+} \mathrm{PF}_{6}{ }^{-}\right)$, were prepared as described previously. 2,2-Dimethoxy-2-phenyl acetophenone (DMPA) (Ciba Specialty Chemicals), was used as received. Perylene (Aldrich) was recrystallized from toluene. Anthracene (Merck) was purified by sublimation.

\section{Photopolymerization}

Typical procedure. First, a solution of $\mathrm{Ph}_{2} \mathrm{I}^{+} \mathrm{PF}_{6}^{-}(0.0365 \mathrm{~g}, 0.005 \mathrm{mmol})$ and DDT $(0.0027 \mathrm{~g}, 0.25 \mathrm{mmol})$ in $0.25 \mathrm{ml} \mathrm{CH}_{2} \mathrm{Cl}_{2}$ was contained in quartz tube (i.d. $=9 \mathrm{~mm}$ ) and filled with dry nitrogen prior to irradiation from Rayonet merry-go-round photoreactor equipped with 16 lamps emitting nominally at $\lambda=300 \mathrm{~nm}$. At the end of irradiation for two and half hours, polymers were precipitated in 10-fold excess hexane and dried in vacuum. All the other polymerization using different onium salts and additives (free radical source or sensitizer) were performed under identical conditions except that the pyrex tubes and the lamps emitting nominally at $\lambda=350$ 
$\mathrm{nm}$ were used in free radical promoted and sensitized polymerizations. Conversions for all samples were determined gravimetrically.

\section{Analysis}

GPC analyses of the polymers were performed at room temperature with a setup consisting of a pump (Waters 600E) and four Waters ultrastryragel columns: HR 5E (2000-4 - $106 \mathrm{~g} / \mathrm{mol}), \mathrm{HR} 4(5000-600000 \mathrm{~g} / \mathrm{mol}), \mathrm{HR} 3$ (500-30 $000 \mathrm{~g} / \mathrm{mol})$, and HR2 $(500-20000 \mathrm{~g} / \mathrm{mol})$. THF was used as the eluent (flow rate $1 \mathrm{~mL}$ min-1), and the detection was carried out with the aid of a Waters 410 differential refractometer. The number-average molecular weights were determined using Polymer Laboratories polystyrene standards. ${ }^{1} \mathrm{H}-\mathrm{NMR}$ spectra were recorded on a Bruker 250 instrument with $\mathrm{CDCl}_{3}$ as a solvent and tertamethylsilane (TMS) as the internal standard. UV-vis spectra were taken on an Ati Unicam spectrophotometer. IR spectra were recorded on a Jasco FT/IR-3 spectrometer on a $\mathrm{NaBr}$ disc.

\section{References}

1. Nemoto, N.; Sanda, F.; Endo, T. Macromolecules 2000, 33, 7229.

2. Crivello, J. V.; Lam, J. H. W. Macromolecules 1977, 10, 1307.

3. Reichardt, C. Chem. Ber. 1966, 99, 1769. 


\section{Legends to Figures}

Figure 1: ${ }^{1} \mathrm{H}$ NMR spectra of 5,5-dimethyl-1,3-dioxane-2-thione (DDT) and the polymer obtained by photoinitiated ring-opening polymerization (Table 1, Run 1)

Figure 2. FT-IR spectra of the polymer (A) obtained by photoinitiated ringopening polymerization (Table 1, Run 1) and 5,5-dimethyl-1,3-dioxane-2thione (B) 

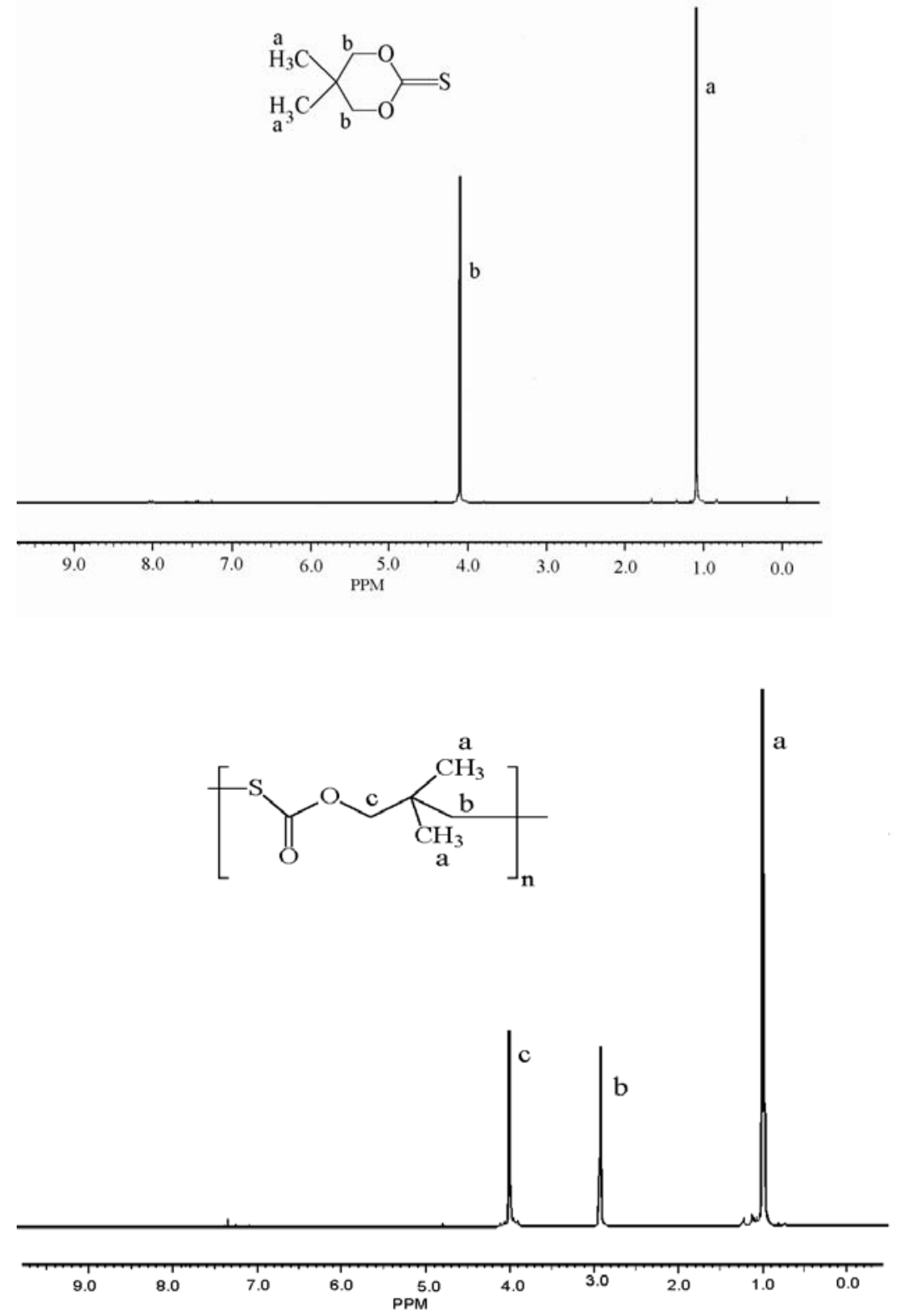

Figure 1. N. Yonet, Y. Yagci, B. Ochiai, T. Endo 


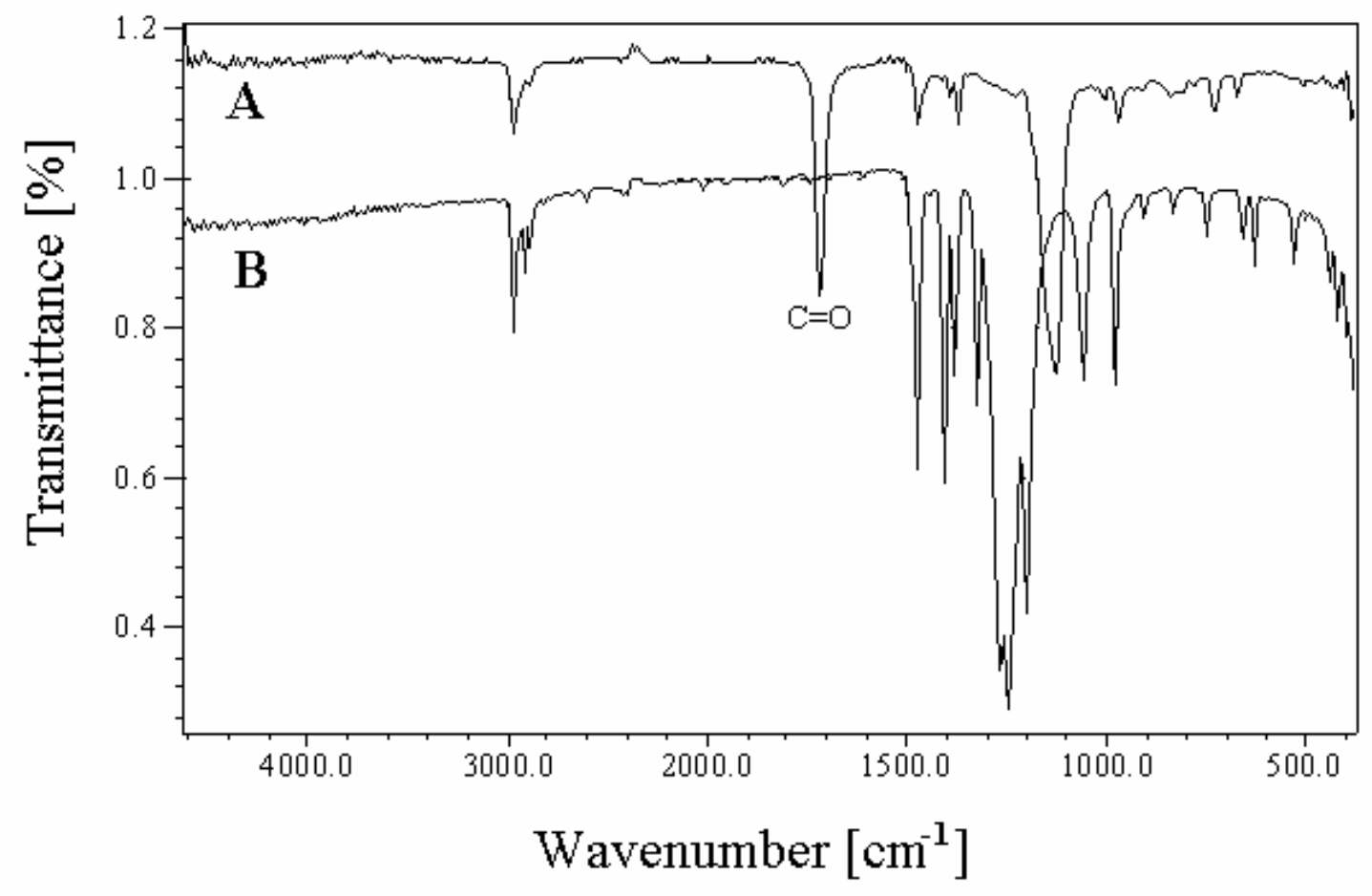

Figure 2. N. Yonet, Y. Yagci, B. Ochiai, T. Endo 